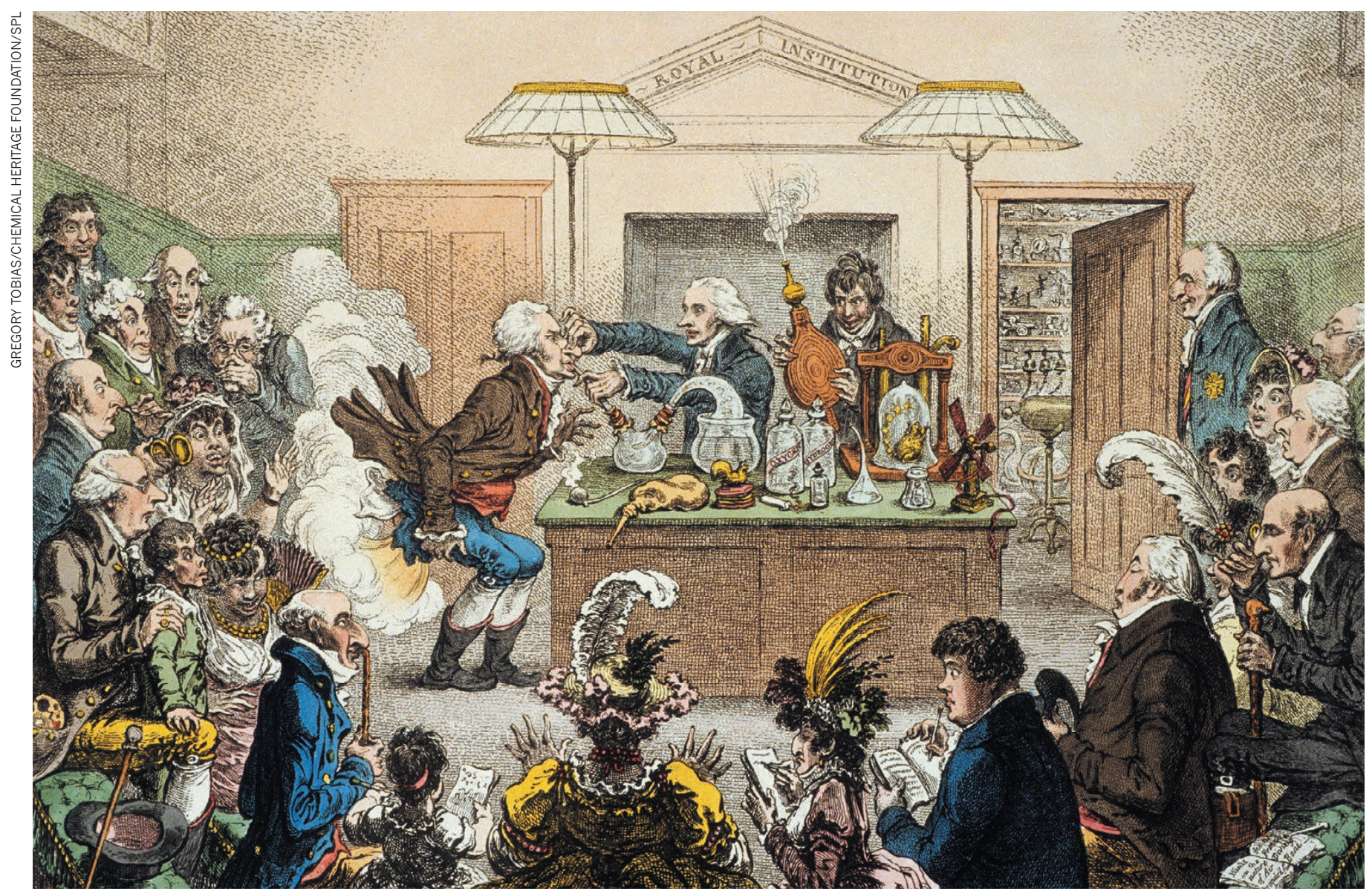

In James Gillray's 1802 cartoon, young Humphry Davy works the bellows at a Royal Institution lecture on pneumatics.

\title{
HISTORY
}

\section{A chemist's contradictions}

\section{Mark Peplow parses a book on Humphry Davy’s dazzling mix of personas.}

$\mathrm{I}$ is November 1799, and Humphry Davy is plastered. Fuelled by alcohol and nitrous oxide, the callow 20 -year-old who within a decade would be feted as the greatest English scientist since Isaac Newton - is seized by an epiphany. "Nothing exists but thoughts!" he cries. "The universe is composed of impressions, ideas, pleasures and pains!"

Historian Jan Golinski recounts this "unprecedented binge" in The Experimental Self, a study that unpicks the chemist's complexities and contradictions. It was Davy the experimentalist who prepared the 'laughing gas' and meticulously recorded its effects. But it was Davy the Romantic poet who gave vent to passionate pronouncements while in the grip of the gas. This amalgam of characteristics helped to establish his reputation as a swashbuckling scientist, a glamorous adventurer at the frontiers of knowledge and experience.
From relatively humble beginnings in Cornwall, Davy ascended to the presidency of the Royal Society in London, winning a knighthood and a baronetcy along the way. He discovered a slew of chemical elements, including sodium and potassium, developed a safety lamp for miners and helped to make chemistry the most fashionable science of

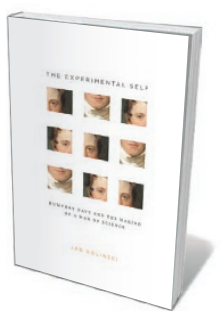

The Experimental Self: Humphry Davy and the Making of a Man of Science

JANGOUINSK

University of Chicago Press: 2016.

the age. He worked at London's Royal Institution (RI), which exploited his fame to raise money, and by 1808 he had used the funding to build a monster 2,000-plate voltaic battery. It was the Large Hadron Collider of its day, a device for carving matter into its constituent parts - and a symbol of national pride, beating the French in a race of voltaic one-upmanship.

As a gifted scientist and charismatic personality, Davy has been a magnet for biographers for two centuries. Golinski takes a new approach. The Experimental Self does not claim to be a comprehensive biography. Instead, it investigates the different identities that Davy constructed, along with those ascribed to him by others: enthusiast, genius, dandy, discoverer, philosopher, traveller.

Golinski's framing echoes Davy's own musings. When he was about 21, Davy wrote a piece in his notebook entitled 'The History of Passion - A Philosophical Narrative', detailing identities that a person might adopt throughout their life. $\mathrm{He}$ also wrote unpublished short stories exploring how character archetypes of 
$>$ the day - such as a student or a lover of nature - might be changed by their life experiences. Golinski cites these "experiments in selfhood" as evidence that Davy thought carefully about his character to create different personas, which he deployed strategically to build his career. He deliberately shaped his speech, manners and deportment to fit into London's high society, and used his talents as a showman and rhetorician to attract huge audiences to his RI lectures on the latest chemical phenomena.

Golinski thus provides a fluid view of Davy, hopping back and forth between different periods of his life. It's a refreshing approach, although it leads to some repetition when the same periods of Davy's life (and even the same incidents) are viewed through different lenses of personality.

Davy the enthusiast developed during the nitrous oxide experiments at the Medical Pneumatic Institution in Bristol, where he drew on the Romantic aesthetic of the sublime to describe the mingled pleasure and fear that the gas triggered in himself and willing volunteers. At the time, 'enthusiast' meant someone who was mentally unbalanced by their passions; Davy used the word about himself to acknowledge how the gas distorted his perceptions. That work soon stirred controversy, with critics ridiculing the effects as a collective hysteria. Public shows of intoxication were lampooned by satirists such as the cartoonist James Gillray.

Once he moved to the RI in 1801 , Davy took a more moderate tone. He still inhaled the gas during lectures, but did not offer it to others. Nevertheless, the lectures quickly became London's hottest ticket. Unlike the learned Royal Society, the institution had a mission to diffuse knowledge

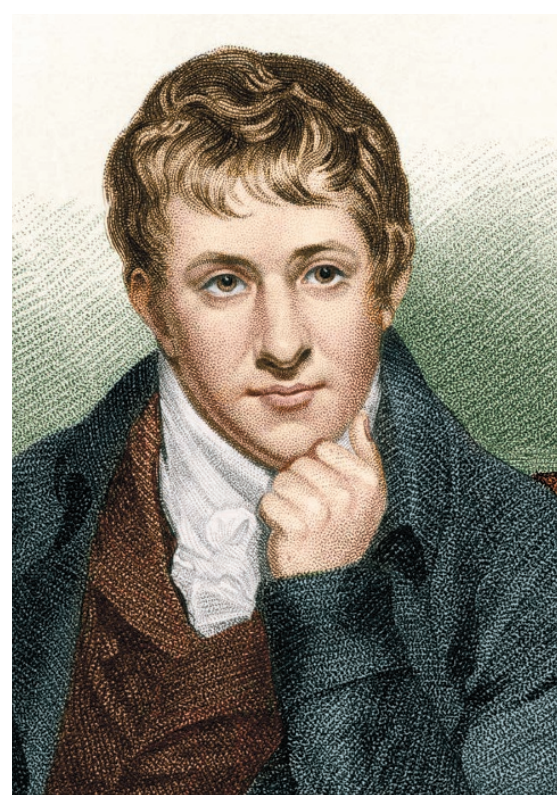

Humphry Davy as a young man.

to the public and exhibit applications of science. Davy's dramatic demonstrations delivered that in spades, offering spectacle and enlightenment in equal measure. The RI's tiered lecture theatre was soon crammed with toffs, including a remarkable number of women.

Davy the genius emerged from this period of public exposure. By emphasizing mannerisms associated with intellectual greatness - eloquence, intensity, expressive movements - he cemented his position as a leading thinker, as well as a chemical showman. Riding a wave of success, he wrote the first volume of a chemistry textbook in 1812 . But Elements of Chemical Philosophy was a flop. By putting himself and his experiments front and centre, the book appeared to be a self-congratulatory celebration of Davy the discoverer, and was roundly criticized by scientists such as chemist Thomas Thomson for lacking the neutrality expected of a sober overview of the field.

Increasingly, Davy's carefully constructed personas caused problems. He became president of the Royal Society in 1820 , but his charisma cut less ice there. His suggestion that women should be allowed to attend evening meetings at the society, as at the RI, was rejected, and even led some to question his masculinity. Meanwhile, a younger generation of scientists resented his dependence on public display and aristocratic patronage. They wanted to be elected to the society on merit, funded by governments rather than lords. As the age of the professional scientist dawned, Davy started to look like an anachronism.

Golinski ends with Davy the traveller. The scientist made a series of continental journeys, conducting research on anything from the chemistry of volcanoes to fresco pigments as he toured the cities of Europe. This was the full Davy roadshow, a heady blend of the scientific and Romantic: he would make poetic notes about the scenery and the weather, and faithfully record their effects on his health. Davy had a series of strokes during these trips, and died in 1829; his final book, Consolations in Travel, was published the next year. It features dialogues between fictional characters - including two reflecting aspects of himself - that explore philosophical questions such as the nature of the soul. "Consolations could be seen as his last virtuoso performance," writes Golinski, "the last of his experiments in selfhood."

Mark Peplow is a science journalist based in Cambridge, UK.

e-mail:peplowscience@gmail.com

\section{England's green and well-known land}

\section{Stuart Pimm extols Richard Fortey's scientific and historical portrait of a beechwood.}

$\mathrm{F}$ ly into London's Heathrow airport, and off to the northwest you will spot a sprinkle of dark-green patches along the undulating fields and hedgerows. The Chilterns are hills sitting on a chalk escarpment, and retain some woodland because of their soils, topography and underlying geology, and the special management that these demand. In 2011, palaeontologist and natural historian Richard Fortey bought 2 hectares of beechwood and bluebells here and began a diary - a "biography", as he puts it.

In Wood for the Trees, Fortey's story unfolds over two interlaced time scales: one a calendar year, the other two millennia of recorded history. His year starts in April, witness to one of those intense English springs that can follow a long, damp winter. Like Robert Browning's famous paean to the season (1845's
DNATURE.COM For more on science in culture see: nature.com/ booksandarts
'Home-Thoughts, from Abroad'), which began, "Oh, to be in England/Now that April's there", Fortey's text is stiff with the names of trees, flowers and birds. There's a pattern here: a very British predilection for natural history. This means that British flora and fauna are exceptionally well documented. I took this for granted as a young naturalist in Derbyshire, only to get a rude shock when looking for field guides in other countries. A well-illustrated guide to the native trees of South Florida (where 